This is the final submitted version. The version of record is:

http://www.tandfonline.com/doi/full/10.1080/09687599.2013.831745\#.U5_3r_ldWSo

\title{
Disability, partnership and parenting
}

Harriet Clarke (Corresponding Author)

Institute of Applied Social Studies

School of Social Policy

University of Birmingham

Edgbaston

Birmingham

B15 2TT

Tel (0121) 4158479

h.clarke@bham.ac.uk

Professor Stephen McKay

Faculty of Health and Social Sciences

University of Lincoln

smckay@lincoln.ac.uk 


\section{Disability, partnership and parenting}

Partnerships and parenthood have important effects on economic, social and psychological wellbeing. We provide new long-term analysis of how disability affects both parental status and partnerships. Analysis of the new Life Opportunities Survey, which is based on social model approaches, demonstrates that disabled people are more likely than non-disabled people to face disadvantages in terms of family formation. Disabled people are more likely to remain single over time, although there is lesser evidence of any differences in rates of relationship breakdown for those who enter them. Allied to these conclusions, disabled adults are less likely to form households where there are dependent children. These conclusions are supported by longitudinal results from the British Household Panel Survey.

Keywords: family, relationships, households

\section{Introduction}

There is little recent British evidence that looks directly at the effect that being a disabled adult has on rates of relationship formation, marriage or cohabitation, family breakup or on other important demographic trajectories (particularly re-partnering, having children). This article presents analysis of the links between disability and experiences of impairment and / or long-standing illness, and their relationship to family formation forming a couple, relationship breakdown, and having children.

The research seeks to quantify the extent of these links. The findings are relevant across a wide range of policy issues, including whether policy and practice supports families which include disabled parents to achieve economic security and family well-being, (which for many may include improved family stability). The analysis is also relevant to barriers to forming relationships and / or becoming parents in the context of disability, which are rarely considered explicitly in policy. Our focus on family forms (family formation and family 
break-up) provides key new evidence relevant to understanding the dynamics of poverty in family lives given the strong links between family structures and low incomes.

The analysis presented here is based on a wide range of research literature and analysis of two different data sets, and it must be acknowledged that definitions of impairment and disability (and operationalisation of these) do vary. Wherever possible our use of terminology and relevant data reflects the distinction between impairment and disability made within disability research and activism within the UK (Barnes 1991). Our understanding of disability is the restriction of access to participation in private and public life as a result of institutional, physical, social and attitudinal barriers. Impairment refers to functional limitations which are caused by physical, sensory or mental impairment (including mental distress). We also recognise that illness, impairment and disability can be experienced together, but the relationship between illness, impairment, disability and social participation is complex and contested by academics and by activists (de Wolfe 2002; Shakespeare, 2006; Hughes, 2009). Impairment can be the consequence of illness, and people living with illness without impairment can experience barriers to social participation (as recognised within the Disability Discrimination Act). Our analysis does not explore relationships between different experiences of disability, impairment and relationship formation, consider disability and sexuality, nor fully disentangle experiences of impairment and ill-health from disability in relation to family life. We hope to identify if there are patterns within our analysis which indicate whether autonomy and private lives is a field requiring greater scrutiny within disability research and policy debates.

This article builds on previous work conducted for the Department of Work and Pensions (ANONYMISED). Here we have analysed baseline data which provides descriptive 
information about the UK population from the Life Opportunities Survey 2009-10, a UK sample survey which is strongly informed by the social model of disability. We also present new analysis of the first 18 waves of British Household Panel Survey (BHPS) 1991-2008/9. The BHPS is an annual survey of households ${ }^{1}$ (including those without and those with dependent children); in most years questions are asked relevant to disability status, using a range of approaches. Whilst the approach has been more focused on health status and functional limitations than social barriers it enables us to consider changes in family status over time.

Before turning to our analysis of these surveys we summarise the context for this work, drawing on literature which presents some of the key issues concerning family experience of disability.

\section{Disability and family formation}

\section{Context}

The Prime Minister's Strategy Unit (2005) report Improving the Life Chances of Disabled People marked a significant juncture in the development of the UK policy agenda, with social model understandings of disability and impairment integral to its presentation of policy issues. The PMSU (2005) report stated its main aim as being that 'By 2025, disabled people in Britain should have full opportunities and choices to improve their quality of life, and will be respected and included as equal members of society' (PMSU 2005, 4). The document is particularly significant given its aim for equality by 2025 has been core to the work of the Office for Disability Issues, and in setting an aim for future equality it presented a life-course perspective; however there are particular emphases in the report, with more 
focus on independent living, services and employment and notably little reference to private relationships including disabled people as partners or as parents. The concept of independent living is inclusive of autonomy including in relation to personal relationships and becoming and being a parent (Morris 1993), however a lack of explicit inclusion of relationships in policy can leave these issue marginalised. Whilst acknowledging that young disabled people moving into adulthood may want to start a family, the PMSU document primarily refers to relationships in terms of fulfilling responsibilities (for care and parenting) whilst not addressing specific issues of what might enable, support or restrict (younger and older) people's choices in relationship formation and family decision making.

The 2006 United Nations Convention on the Rights of People with Disabilities, which the UK ratified in 2009, does include a discussion of disability, family life and fertility. It advocates that States take measures to eliminate discrimination faced by disabled people 'in all matters relating to marriage, family, parenthood and relationships' (UN 2006, article 23). Promoting understanding of disabled people's experiences in the context of their relationships (including as parents and as partners) and understanding the experience of disability over time, in a dynamic family-focused context, are important to securing this ambition, within the UK and internationally.

\section{Family relationships in disability and impairment research}

There is limited social policy evidence concerning the specific effects of impairment and disability experiences on the dynamics of family forms: the wider field concerning family life and disability is uneven, with a significant literature existing across health and social care policy and practice in relation to families which include disabled children. In contrast there is a relatively small though important literature on disabled adults' experiences of family life 
and parenting (e.g. see Wates 2003; Olsen and Clarke 2003; Olsen and Tyers, 2004; Morris and Wates 2006; CSCI 2009). This has predominantly focused on the way in which adults' and children's services respond to parent and family support requirements and the extent to which disabled people's parenting role is recognised, supported or undermined. Concerns have also been raised about child protection responses to disabled parents where insufficient support has been available, particularly in relation to parents with learning disabilities (James 2004; Booth, Booth \& McConnell 2006; Tarleton, Ward \& Howarth, 2006). Much of the disability and parenting research work conducted has been concerned with experiences of parenting and of services, rather than mothering or fathering in the context of wider roles and relationships. Further work to develop our understanding of how disability experiences are gendered within partnership and parenting relationships would be particularly valuable (Kilkey and Clarke 2010).

More broadly, partnering and parenting have been identified as important elements of disability analysis in social policy. Priestley $(2000 ; 2003)$ has demonstrated the importance of understanding disability within a life course perspective, with partnering and parenting central to an idealised construction of independent adulthood. Disability studies writing and research that has focused on sexuality has provided an invaluable focus on private lives in social context (Shakespeare, 2000; Sherry, 2004; Abbott, 2012). Lacking to date is in-depth analysis of people's patterns of relationship formation where disability is considered, and what might be termed access to choices concerning partnering and / or parenting roles (for disabled and non-disabled people). This is not to suggest that partnership and parenthood are desired statuses for all or raise specific issues for most disabled people. Neither does this reflect a concern to prioritise one form of relationship, for example in heteronormative and gender normative terms (Rembis 2010). It is however important to recognise that the 
experience of disability can include barriers to self-determination in personal and familial relationships and to consider how analysis of available quantitative data can inform future policy and research.

The analysis offered here is not service orientated and is instead commensurate with the call by Fox (2010) to move beyond a policy focus on choice and control over services, to concern with 'access to ordinary life chances, such as paid employment, active citizenship and participation in family life (beyond the provision or receipt of care)' (Fox 2010, p 46: emphasis added). Our concern, with patterns of family formation and dissolution (where family is broadly defined), is of course also relevant to disability policy including the impact of welfare policy on disabled peoples' and their families' lives, and the extent to which existing supports for independent living is sufficient to ensure personal autonomy in relationships.

Much of the research which has been conducted on partnership relationships and disability has been impairment specific. Whilst this often has a clinical overtone (focusing on impairment or prior illness as the 'cause' of outcomes, rather than looking at the impact of disabling barriers), examining such work can enable us to begin to untangle some of the complexities of disability in a life-course context. For example, we can identify that there may be different consequences of congenital and early childhood onset impairment, and later impairment onset, and sudden onset of impairment and fluctuating conditions and impairments.

Research exploring young disabled people's experience of moving into adulthood has often focused on social care services transitions, education and employment; however some studies 
have included issues of partnering and parenting. Olsen and Clarke (2003) spoke to disabled parents (predominantly mothers) some of whom had been given negative messages as disabled children concerning their anticipated or hoped for roles as partners or parents. Hendley and Pascall (2001) identified in their sample of disabled people aged between 21 and 35 that some young women faced opposition to plans for marriage or cohabitation, and that whilst a small number of their participants were in couple relationships and / or had children, young disabled people could lack support outside their families which would enable independent adulthood (including choosing to become partners and/or parents).

In relation to childhood onset of impairment or health concerns, the most extensive literature has been concerned with childhood cancer and later marital status. Research in this area has tended to be grounded in medical and cancer literatures (with cancer as an acute health experience with potentially long-term impacts), rather than having an explicit impairment and disability focus. The extent of this literature (in contrast to the smaller literature on childhood impairment and later marital status) may reflect the longitudinal data available in relation to cancer, a medical and individual focus on recovery and life course opportunities, and the marginal position of concerns with access to parenting and partnering within disability research. However, there are some references within the childhood cancer literature to cancer-related impairment experience in life-course context. This work has consistently found that people who had experienced childhood cancer were as a whole less likely to marry (e.g. Byrne et al 1989; Pastore et al 2001; Rauck et al 1999; Frobisher et al 2007). In relation to childhood cancer, it has been suggested that fertility concerns might impact relationship formation; however analysis of the British Childhood Cancer Survivor Study (Frobisher et al 2007) did not support this. 
The literature looking at experiences of adulthood onset impairment raises issues in relation to impairment specific aspects (particularly fluctuation of conditions, and nature of onset). Much research focuses on sudden-onset events, particularly injury - with fluctuating impairments and health concerns marginal in the literature. A significant amount of work has been conducted internationally and in the UK in relation to impairment through sudden injury and marriage experience (rather than whether people enter into marriage or other partnership relationships or not); examples of such work in the UK include explorations of the 'role change' women partners of men with head injury report (Gosling and Oddy 1999) and spouse experience of a partner's spinal cord injury involving a move from partner to carer role (Dickson et al 2010). Such work is individually and psychologically orientated rather than concerned significantly with social barriers and socially created relationship change or difficulties. Alternatively, there are arguably more inclusive social research literatures (as regards types of impairment) concerning experiences of disability within families focused on 'carer' roles within relationships; whilst this research material provides insight into some aspects of some people's relationships in the context of disability, carer focused work can often- just as the more clinical material noted above - risk being limited to a concern with dependence and relationship 'costs' rather than examining people's shared experiences of disability and interdependence and / or implications for forming and maintaining personal and familial relations.

\section{Relationship maintenance and dissolution}

Positive aspects of relationships in the presence of health difficulties and / or impairment are only very rarely considered within the literature. Where they are addressed, it is often in relation to cost / benefit forms of interpretation, reporting elements of loss and elements of strengthening within relationships. Such an approach may not help us to fully 
understand interdependent, care-based (rather than 'carer'/'cared for') relationships and the features which support or serve to undermine them. Within policy, practice and research focusing on adults' support requirements, the term 'carer' masks the pre-existing relationships (e.g. partner, wife) which is likely to be most important to individuals: partnership relations may be put under strain if disabled people and their partners do not retain the opportunity to negotiate and reciprocate care within their relationship (Parker and Clarke, 2002) and to experience both mutual dependence and autonomy (Kröger, 2009).

Loss of employment and independent income may be an additional risk which impacts on relationships as a result of disability. Charles and Stephens (2004) conducted analysis of US panel data and found that although disability had long term impacts on economic well-being, it did not increase the likelihood of divorce. Job loss did, particularly when the disabled person experienced individual lay-off rather than losing work as part of mass redundancy. Representations of adulthood which stress employment as a marker of adulthood status may be damaging to people's experience of their relationship when work is not accessed or maintained (by disabled people or their partners). Access to and appropriate adjustments within a work environment and independent income for disabled people (including those not in work) are important ways of ensuring disabled people and their partners have an economic base for choices within their relationships (such as to maintain or leave partnerships).

\section{Disability and family poverty}

Disability based risks of child poverty have been recognised in a number of policy documents, including the PMSU (2005) Improving the Life Chances of Disabled People. Parental disability has been identified as increasing the risk of families (and therefore children) living in poverty compared to households which do not include disabled parents. 
Strickland and Olsen (2006) report, from their analysis of a number of data sources, that this increased risk of family poverty holds true for both dual and lone parent families, and can most strongly be associated with worklessness (i.e. lack of access to paid work); further, disabled parents who do have paid work are more likely than non-disabled parents to be in low-paid, insecure and part time work. Preston (2006) reports from research with disabled parents that there are several barriers to employment (and maintaining employment), including discrimination, employer recognition of skills, access to training, combining care services and employment, benefit concerns and access to appropriate childcare. She reports that lone disabled parents can face particular difficulties in combining work and parenting.

Some elements of the relationship between presence of impairment and socio-economic disadvantage have also been summarised by Morris and Wates (2006) in their knowledge review for the Social Care Institute for Excellence. They report that parents living in the poorest communities are at increased risk of long-term health difficulties, mental ill-health and disability, and that inappropriate or poor housing is associated with the presence of impairment or illness.

There are a number of important variables which may intervene in the relationship between cohabiting partnerships (including marriage) and disability, including poverty and 'worklessness' (here defined as lack of paid work or insecure and fragmented access to paid work). The impact of economic hardship and worklessness on relationship status may be different for men and for women, particularly as paid and un-paid work roles remain gendered and women remain more likely than men to have care and domestic responsibilities as key roles both within households and within wider family networks. 


\section{Methods and data}

Until recently, surveys have focused either on health status, or on disability as a 'functional' descriptive of an individual's ability to conduct activities, including activities of daily living (ADLs). Over the last fifteen years there have been continued developments in survey questions, which have sought to (partially, at least) reflect disability definitions which are concerned with restricted access to public and private roles which result from disabling barriers.

The new Life Opportunities Survey (LOS) has perhaps done the most to be congruent with a social model of disability. The data collectors say that 'It is the first major social survey to explore disability in terms of the social barriers to participation that people in Great Britain experience' (ONS 2011: p. 1), rather than 'measuring' disability as if it were the experience of impairment or a health condition. The first wave of the LOS was collected between 2009 and 2010 following significant development work: a reference group formed of 60 disabled people were regularly consulted during the development of the survey. There was also qualitative testing of the questionnaire prior to its introduction in a standard structured format. At its first wave, a total of around 18000 adults were interviewed, of whom close to 5,000 would meet the definition under the Disability Discrimination Act (DDA) as being disabled. In this analysis we draw on the LOS to provide current, cross-sectional results. This indicates the prevalence of different family forms and whether there are children, and how this is associated with disability status.

It is also important to bring in a longitudinal perspective where possible, and for this we use the British Household Panel Survey (BHPS). The BHPS did not aim to measure experiencing disability in the same way as LOS. However it did capture some information that may be 
regarded as useful. In particular respondents were asked if their health limited their daily activities, compared with someone of the same age. The reference to heath, in this context, is clearly unhelpful but we regard it as important to examine the longitudinal data that is available and to retain reference to the original terms used in the collection of data from this and other sources, in order to be able to analyse them appropriately and to make clear the strengths and limitations of the sources for this kind of analysis. This includes the use of terms which refer to long-standing illness or limiting long term illness, as a signifier of increased likelihood of experiencing impairment and disability.

\section{Results}

In this section we present results that indicate differences in partnership and parenting outcomes for disabled people compared to others. In particular we identify a greater chance of remaining single rather than entering into a partnership, based on both cross-sectional and longitudinal evidence. This may be a key factor in the lower proportion of disabled people who have dependent children in their household.

\section{Partnership status}

Analysis of the Life Opportunities Survey (Table 1) shows that most people aged under 30 were single, irrespective of whether they were disabled people. However the proportion who are single then tends to fall quite sharply for those aged over 30, as marriage (including civil partnerships) and cohabitation become more common. Whilst this is crosssectional data the snapshot suggests that disabled young people do not move into couples as quickly as non-disabled adults. Whilst only 18 per cent of non-disabled people in their $30 \mathrm{~s}$ are single, this is at 35 per cent for disabled people. For those in their 40 s 18 per cent of disabled people report as single, compared with 12 per cent of those who were not disabled. 
The proportions of those who are single vary less between disabled and non-disabled people for those aged 60 or older.

A corollary of these patterns in single status is a lower proportion of disabled people who are married compared to non-disabled people, particularly for those in middle age. Indeed for those aged between 30 and 59 there is almost a gap of twenty percentage points in rates of being married. So for those aged 30-39, some 57 per cent of those reporting as non-disabled are married, compared with 37 per cent of disabled people. This gap is almost as large for those in their 40 s $(65 \%$ versus $49 \%)$.

Only part of the gap in rates of marriage was due to more disabled people remaining single. Disabled people were also rather more likely to exit marriage through divorce or separation. For those in their 40s and 50s, some 20 per cent of disabled people were divorced or separated, or roughly double the proportion of non-disabled people. This difference, albeit at a lower level, is also found among those at older ages.

\section{[Table 1 approximately here]}

Overall, disabled people were less likely to be married, and the pattern is consistent with two contrasting reasons for this. First, they were more likely to be single and less likely to have become married. Second, even among those who had become married, rates of divorce (or separation) were higher among disabled people.

These differences in marital and relationship status are more closely linked to the concept of disability (as measured in the DDA) than to impairments or the limitations measured by the 
International Classification of Functioning, Disability and Health (ICF). Table 2 compares the rates of marriage of disabled people by age, compared with the LOS sample as a whole and with those categorised as having an impairment or a limitation measured by a section of questions related to the ICF. For those aged 30-59, the greatest difference in rates of marriage from the population as a whole was for disabled people. Rates of cohabitation are not shown in this table, but differ much less according to either disability (as shown in Table 1) or impairment. $^{2}$

\section{[Table 2 approximately here]}

\section{Partnership status - longitudinal description}

The BHPS is a longitudinal survey which allows us to track people over time to see how their relationship status changes from 1991 onwards. This survey was not designed to measure disability as cogently as the LOS. However it does ask about the presence of any limiting long-term illness or 'disability', which provides an approximate identification of a subsample likely to experience disability.

In Table 3 we show the later relationships states of those who in 1991 were either (a) single and never-married, or (b) married. We track those remaining in the survey and show results for 1995, 2000 and 2005. The upper panel of Table 3 shows that disabled people (as conceptualised in the BHPS) were likely to remain single for rather longer than non-disabled people. By the year 2000, more than half of the non-disabled sample were no longer single, but had instead formed a couple or entered a marriage (with $49 \%$ remaining single). Among disabled people two thirds (65\%) remained single. This difference was maintained even by the year 2005 (albeit the sample size, $n=68$, is relatively low). We can conclude that disabled 
people tend to remain single, never-married, for longer than non-disabled people. This evidence is based on measuring disability only at the starting point (1991).

The lower half of Table 3 provides a longitudinal picture of the stability of marriage, again comparing those who had a limiting long-term illness in 1991 with those who did not. This time, there appears to be few differences in the rates of marriage dissolution - with only a few percentage points of difference, and tending to suggest disabled people were not disadvantaged in this regard. This is consistent with the difference in marriage rates, found in cross-sectional data, being more the result of a delayed exit from single status, than any increase in the dissolutions of those marriages that are formed.

\section{[Table 3 approximately here]}

\section{Parenting status}

We should also consider the extent to which there appears to be an effect of adulthood disability on parenting, including whether individuals become parents in the first place, and when parenting occurs within the life-span. Given the apparent marriage gap during the predominant child-rearing years, it may be that we additionally find a parenthood gap between those with a limiting long term illness and those without. Here we consider patterns in relation to adult impairment and parental status (in relation to presence of dependent children).

There appears to be a strong link between the presence of dependent children in the household, and being a disabled person (Table 4). The proportion of people with children in their household was 63 per cent for those in their 30s and not disabled, compared with 49 per 
cent for disabled people in the same age group. For those in their forties the gap was close to ten percentage points. There were also differences between those with and without impairments, of a similar direction but of smaller size for those in their thirties. There was also some limited evidence that disabled people were more likely to have children at a younger than average age, and clearer evidence of the same pattern for those identified as having impairments. Having children when young is generally regarded as a marker for disadvantage.

\section{[Table 4 approximately here]}

As in the preceding section, we may also examine the longitudinal pattern of having children. Table 5 shows respondents who did not have children in their households in 1991, and the proportion having children in their households in later years. So, by 1995 , only three per cent of those reporting as disabled people in 1991 had children in their households, compared with ten per cent among the non-disabled sample members. This disparity continues with data collected in 2000 and 2005.

\section{[Table 5 approximately here]}

\section{Discussion and conclusions}

Whilst any meaningful definition of independent living for disabled people includes choice and control in relation to personal relationships and family formation there has been a lack of consideration of this within social policy research. More psychologically orientated studies have tended to focus on partners of people who become disabled during a marriage relationship, and the implications of a significant 'carer' role in ways which do not 
problematise this conceptualisation. Over the past two decades there has been increased visibility of disabled parents' and their families' experiences through research and the work of disabled parents organisations including Disabled Parents Network (DPN) and Disability, Pregnancy and Parenthood International. Much of the focus of disability and parenting research has been on support for parenting by current parents (and more often mothers than fathers) rather than family formation. Whilst disabled parents organisations have more clearly identified becoming a parent as an issue of importance to some disabled people, social policy (and social policy research) is often more concerned with current relationship and parenting statuses rather than opportunities and constraints and change over time. The lack of research considering disabled people's experience of impairment onset and disability in the context of partnership relationships, or of disabled people's experience of becoming partners or parents, is underlined further by limited consideration of personal relationships and disability within social policy. Becoming a parent or the experiences of partnership or partnership dissolution have arguably been largely treated as private decisions which do not require consideration in relation to social organisation and disability except in the context of 'risk', 'vulnerability', or 'family troubles'.

Our analysis indicates that family formation is a field requiring greater scrutiny within disability research. The cross-sectional data (LOS) provides findings which can be closely discussed with reference to Disability Discrimination Act and social model conceptions of disability, but cannot be used to report changes (in either experience of disability or family formation) over time. The BHPS is a longitudinal survey, but provides a less precise way of conceptualising disability. Here we have been able to report that disabled people have a greater chance of remaining single rather than entering into a partnership, based on both the cross-sectional and longitudinal data. However BHPS analysis additionally suggests that 
unmarried disabled people tend to be less likely to marry during the period of the survey, but that married disabled people were not substantially more likely to experience divorce. The LOS and BHPS analyses found that disabled people were less likely to have children in their household, with the LOS analysis also suggesting that disabled people who were parents were more likely to have children at a younger than average age.

Further building research knowledge in this field may help to confront narrow policy orientations to 'family' (often focused on notions of risk and vulnerability, responsibilities, and 'protection' through intervention). This could complement developing debates concerning private experiences of sexuality, gender and disability in social context. The analysis presented here suggests that future work should further examine disability and family formation and that should be used to inform debate on how policy could address barriers to self-determination in personal and familial relationships.

\section{Notes}

1. The British Household Panel Survey has now been incorporated into the Understanding Society Survey

2. Despite these clear differences, disabled people were not much more likely than average to regard their personal lives as being restricted in any particular way -12 per cent of disabled people thought their personal relationships were restricted, compared with three per cent of non-disabled people. The set of restrictions included financial ones and a lack of time, in addition to being disabled or having an impairment.

\section{REFERENCES}

Abbott, D. 2012. Nudge, nudge, wink, wink: love, sex and gay men with intellectual disabilities - a helping hand or a human right? Journal of Intellectual Disability Research. doi:

$10.1111 / \mathrm{j} .1365-2788.2012 .01642 . x$ 
Barnes, C. 1991. Disabled People in Britain and Discrimination: A Case for Antidiscriminatory Legislation. London: Hurst \& Co.

Booth, T., Booth, W. And McConnell, D. 2005. The prevalence and outcomes of care proceedings involving parents with learning difficulties in the family courts. Journal of Applied Research in Intellectual Disabilities 18, no. 1: pp 7-17.

Byrne, J., T.R. Fears, S.C. Steinhorn, J.J. Mulvihill, R.R. Connelly, D.F. Austin, G.F. Holmes, F.F. Holmes, H.B. Latourette, M.J. Teta, M.J. et al. 1989. Marriage and divorce after childhood and adolescent cancer. Journal of the American Medical Association 262, no. 19: pp 26932699.

Charles, K. and M. Stephens. 2004. Disability, job displacement and divorce. Journal of Labor Economics 22, no. 2: 489-523.

CSCI. 2009. Supporting Disabled Parents: A Family or a Fragmented Approach? London: Commission for Social Care Inspection.

de Wolfe, P. (2002) Private tragedy in social context? Reflections on disability, illness and suffering. Disability \& Society 17, no. 3: 255-67.

Dickson, A., O'Brien, G., Ward, R., Allen, D., and O'Carroll, R. 2010. The impact of assuming the primary caregiver role following traumatic spinal cord injury: an interpretative phenomenological analysis of the spouse's experience. Psychology and Health 25, no. 9: 1101-1120. 
Fox, A. 2010. From independence to interdependence: integration means 'think family'. Journal of Integrated Care 18, no 2: 41-48.

Frobisher, C., E.R. Lancashire, D.L. Winter, H.C. Jenkinson, and M.M. Hawkins. 2007. Long-term population-based marriage rates among adult survivors of childhood cancer in Britain. International Journal of Cancer 121, no. 4: 856-855.

Gosling, J. and M. Oddy. 1999. Rearranged marriages: marital relationships after head injury. Brain Injury 13, no. 10: 785-796.

Hendley, N. and Pascall, G. 2001. Disability and Transition to Adulthood: Achieving Independent Living. Brighton: Pavillion Publishing for the Joseph Rowntree Foundation.

Hughes, B. 2009. Disability activisms: social model stalwarts and biological citizens. Disability \& Society 24, no. 6: 677-688.

James, H. 2004. Promoting effective working with parents with learning disabilities. Child Abuse Review 13, no. 1: pp 31-41.

Kilkey, M. and Clarke, H. 2010. Disabled men and fathering: opportunities and constraints. Community, Work and Family 13, no. 2: 127-146.

Kröger, T. 2009. Care research and disability studies: nothing in common?. Critical Social Policy 29, no. 3: 398-420. 
Morris, J. (1993). Community Care or Independent Living?. York: Joseph Rowntree Foundation.

Morris, J. and M. Wates. 2006. Supporting Disabled Parents and Parents with Additional Support Needs. Knowledge Review 11. London: Social Care Institute for Excellence.

Office for National Statistics. 2011. Life Opportunities Survey: Wave 1 Technical Report 2009/11. Newport: ONS.

Olsen, R. and H. Clarke. 2003. Parenting and Disability: Disabled Parents Experiences of Raising Children. Bristol: Policy Press.

Olsen, R. and Tyers, H. 2004. Think Parent: Supporting Disabled Adults as Parents. London: National Family and Parenting Institute.

Parker, G. and Clarke, H. 2002. Making the ends meet: do carers and disabled people have a common agenda? Policy \& Politics 30, no 3: 347-359.

Pastore, G., M.L. Mosso, C. Magnani, L. Luzzatto, M. Bianchi and B. Terracini. 2001. Physical impairment and social life goals among adult long-term survivors of childhood cancer: a population-based study from the childhood cancer registry of Piedmont, Italy. Tumori 87, no. 6: $372-378$. 
Preston, G. 2006. Living with disability: a message from disabled parents. Chapter 4 in G. Preston (ed.). A Route Out of Poverty: Disabled People, Work and Welfare Reform. London: Child Poverty Action Group.

Priestley, M. 2000. Adults only: disability, social policy and the life-course. Journal of Social Policy 29, no. 3: 421-39.

Priestley, M. 2003. Disability: A Life Course Approach. Oxford: Blackwell.

Prime Minister's Strategy Unit. 2005. Improving the Life Chances of Disabled People. London: Cabinet Office.

Rauck, A.M., D.M. Green, Y. Yasui, A. Mertens and L.L. Robison. 1999. Marriage in the survivors of childhood cancer: a preliminary description from the Childhood Cancer Survivor Study. Medical and Paediatric Oncology 33, no 1: pp 60-63.

Rembis, M. 2010. Beyond the binary: rethinking the social model of disabled sexuality. Sexuality and Disability 28, no 1: pp 51-60.

Shakespeare, T. 2000. Disabled Sexuality: Towards Rights and Recognition. Sexuality and Disability 18, no. 3: pp 159-166.

Shakespeare, T. (2006). Disabilitly Rights and Wrongs. Abingdon: Routledge. 
Sherry, M. 2004. Overlaps and contradictions between queer theory and disability studies. Disability \& Society 19, no. 7: pp 769-783.

Strickland, H. and R. Olsen. 2006. 'Children with disabled parents' in Gabrielle Preston (ed.) A Route Out of Poverty? Disabled People, Work and Welfare Reform, London: CPAG.

Tarleton, B., Ward, L., and Howarth, J. 2006. Finding the Right Support? A Review of Issues and Positive Practice in Supporting Parents with Learning Disabilities and their Children. London: The Baring Foundation.

United Nations. 2006. Convention on the Rights of Persons with Disabilities and Optional Protocol. New York: United Nations.

Wates, M. 2002. Supporting Disabled Adults in their Parenting Role. York: Joseph Rowntree Foundation.

NOTE: One reference to add as referred to as anonymised in text. 
Column percentages

\begin{tabular}{|c|c|c|c|c|c|c|c|c|}
\hline Marital status & $18-29$ & 30-39 & $40-49$ & $50-59$ & $60-69$ & $70-79$ & 80+ & All \\
\hline \multicolumn{9}{|c|}{ No DDA disability } \\
\hline Single & 64 & 18 & 12 & 7 & 5 & 6 & 10 & 23 \\
\hline Cohabitation & 21 & 20 & 11 & 8 & 4 & 1 & - & 13 \\
\hline Married & 14 & 57 & 65 & 72 & 74 & 62 & 34 & 53 \\
\hline $\begin{array}{l}\text { Divorced or } \\
\text { separated }\end{array}$ & 1 & 5 & 10 & 11 & 9 & 8 & 6 & 7 \\
\hline Widowed & - & $*$ & 1 & 3 & 8 & 23 & 50 & 4 \\
\hline Base & 2598 & 2382 & 2590 & 2111 & 1720 & 903 & 323 & 12627 \\
\hline
\end{tabular}

\begin{tabular}{|c|c|c|c|c|c|c|c|c|}
\hline \multicolumn{9}{|c|}{ Has DDA disability } \\
\hline Single & 61 & 35 & 18 & 11 & 6 & 4 & 6 & 14 \\
\hline Cohabitation & 24 & 21 & 12 & 6 & 4 & 2 & 1 & 7 \\
\hline Married & 12 & 37 & 49 & 59 & 64 & 56 & 34 & 50 \\
\hline $\begin{array}{l}\text { Divorced or } \\
\text { separated }\end{array}$ & 3 & 7 & 20 & 20 & 15 & 12 & 6 & 13 \\
\hline Widowed & - & - & 2 & 3 & 11 & 26 & 54 & 15 \\
\hline Base & 269 & 375 & 661 & 828 & 1044 & 967 & 670 & 4814 \\
\hline
\end{tabular}

Source: own analysis of the Life Opportunities Survey (March 2009 to June 2010).

Note: cohabitation included same sex as well as opposite sex relationships, whilst 'married' includes civil partnerships. 
Table 2 'Marriage gaps': marriage rates, disability and impairments

Column percentages

\begin{tabular}{lcccccccc} 
Group & $\mathbf{1 8 - 2 9}$ & $\mathbf{3 0 - 3 9}$ & $\mathbf{4 0 - 4 9}$ & $\mathbf{5 0 - 5 9}$ & $\mathbf{6 0 - 6 9}$ & $\mathbf{7 0 - 7 9}$ & $\mathbf{8 0 +}$ & All \\
\hline Whole sample & 13 & 53 & 62 & 68 & 70 & 59 & 34 & 51 \\
$\begin{array}{l}\text { ICF limitation } \\
{[\mathrm{n}=5859]}\end{array}$ & 16 & 51 & 54 & 61 & 63 & 51 & 34 & 47 \\
$\begin{array}{l}\text { Has } \\
\begin{array}{l}\text { impairments } \\
{[\mathrm{n}=5250]}\end{array}\end{array}$ & 13 & 43 & 53 & 60 & 65 & 58 & 32 & 50 \\
$\begin{array}{l}\text { DDA disabled } \\
{[\mathrm{n}=4814]}\end{array}$ & 12 & 37 & 49 & 59 & 64 & 56 & 34 & 50 \\
\hline
\end{tabular}

Source: own analysis of the Life Opportunities Survey (March 2009 to June 2010).

Note: cohabitation included same sex as well as opposite sex relationships, whilst 'married' includes civil partnerships. 
Table 3 Partnership status - longitudinal description of single and married status, by disability status in 1991.

Row percentages - remaining in the initial status

\begin{tabular}{|c|c|c|c|c|}
\hline & 1991 & 1995 & 2000 & 2005 \\
\hline \multicolumn{5}{|l|}{$\begin{array}{l}\text { (a) Proportion } \\
\text { remaining single } \\
\text { over time ( } \underline{\text { those }} \\
\text { single in } 1991)\end{array}$} \\
\hline $\begin{array}{l}\text { With limiting } \\
\text { long-term illness }\end{array}$ & $100 \%$ & $81 \%$ & $65 \%$ & $49 \%$ \\
\hline Others & $100 \%$ & $73 \%$ & $49 \%$ & $38 \%$ \\
\hline Base: 1lti & 171 & 119 & 92 & 68 \\
\hline Base: others & 1794 & 1234 & 1061 & 913 \\
\hline \multicolumn{5}{|l|}{$\begin{array}{l}\text { (b) Proportion } \\
\text { remaining married } \\
\text { over time (those } \\
\text { married in } \underline{1991})\end{array}$} \\
\hline $\begin{array}{l}\text { With limiting } \\
\text { long-term illness }\end{array}$ & $100 \%$ & $98 \%$ & $93 \%$ & $92 \%$ \\
\hline Others & $100 \%$ & $96 \%$ & $92 \%$ & $90 \%$ \\
\hline Base: 1lti & 738 & 462 & 372 & 290 \\
\hline Base: others & 5082 & 3733 & 3216 & 2719 \\
\hline
\end{tabular}

Source: own analysis of the British Household Panel Survey. 
Table 4 Proportion with dependent child(ren) in household

Column percentages

$\begin{array}{lllllllll}\text { Disability, } & \mathbf{1 8}-29 & \mathbf{3 0 - 3 9} & \mathbf{4 0 - 4 9} & \mathbf{5 0 - 5 9} & \mathbf{6 0 - 6 9} & \mathbf{7 0 - 7 9} & \mathbf{8 0}+ & \text { All }\end{array}$ impairment status

\begin{tabular}{lcccccccc}
\hline $\begin{array}{l}\text { No DDA } \\
\text { disability }\end{array}$ & 39 & 63 & 61 & 22 & 3 & 1 & 1 & 38 \\
DDA disability & 41 & 49 & 52 & 19 & 4 & 2 & 2 & 19 \\
& & & & & & & & \\
No impairment & 38 & 63 & 62 & 22 & 3 & 1 & 1 & 37 \\
Has & 45 & 56 & 52 & 19 & 4 & 2 & 2 & 24
\end{tabular}

impairments

Source: own analysis of the Life Opportunities Survey (March 2009 to June 2010). 
Table 5 Longitudinal description of child status, by disability status in 1991

\section{(among those with no children in 1991)}

Row percentages - proportion with children

\begin{tabular}{lllll}
\hline & 1991 & 1995 & 2000 & 2005 \\
\hline $\begin{array}{l}\text { Proportion with } \\
\text { children }\end{array}$ & & & & \\
$\begin{array}{l}\text { With limiting } \\
\text { long-term illness }\end{array}$ & $0 \%$ & $3 \%$ & $8 \%$ & $10 \%$ \\
Others & $0 \%$ & $10 \%$ & $19 \%$ & $23 \%$ \\
Base: llti & 1075 & 666 & 490 & 378 \\
Base: others & 5478 & 3945 & 3356 & 2846 \\
\hline
\end{tabular}

Source: own analysis of the British Household Panel Survey. 


\section{RESEARCH ARTICLE - POINTS OF INTEREST}

\section{Disability, Partnership and Parenting}

- Social policy and research often focuses on individual access to services or to public roles and spaces.

- Secondary data analysis of new large sources helps to identify patterns in private roles, particularly in partnership relationships and parenting.

- Analysis suggests that disabled people may be more likely to remain single rather than live with a partner when compared to non disabled people. They may be less likely to be in households where there are dependent children.

- Once disabled people are in relationships, their stability seems similar to that of other people.

- There may be barriers to family life (parenthood and partnering) for some disabled people that require further attention from researchers and policy makers. 